\title{
Osteomielite tuberculosa imitando um tumor ósseo lítico: Relato de dois casos e revisão da literatura*
}

\section{Tuberculous Osteomyelitis Mimicking a Lytic Bone Tumor: Report of Two Cases and Literature Review}

\author{
I. Gede Eka Wiratnaya ${ }^{1}$ I. Wayan Restu B. Susila ${ }^{1}$ Dwijo Anargha Sindhughosa ${ }^{2}$ \\ ${ }^{1}$ Departamento de Cirurgia Ortopédica e Traumatológica, Sanglah General \\ Hospital-Medical Faculty of Udayana University, Denpasar, Indonésia \\ 2 Faculdade de Medicina, Udayana University, Denpasar, Indonésia \\ Endereço para correspondência I. Gede Eka Wiratnaya, Department \\ of Orthopedic and Traumatology Surgery, Sanglah General Hospital- \\ Medical Faculty of Udayana University, Denpasar, Indonesia \\ (e-mail: igedeekawiratnaya@gmail.com).
}

Rev Bras Ortop 2019;54:731-735.

\section{Resumo \\ Palavras-chave \\ - neoplasias ósseas/ diagnóstico \\ - biópsia \\ - agulha fina/métodos \\ - tuberculose \\ - osteoarticular/ diagnóstico \\ - agentes antibacterianos/uso terapêutico}

A osteomielite tuberculosa é uma forma incomum de tuberculose (TB) e o acometimento isolado da articulação do punho pelo TB é particularmente raro. Os sintomas e a manifestação clínica imitam outras doenças; portanto, um diagnóstico cuidadoso é necessário. Os autores apresentam dois casos de pacientes com massa nas partes moles e lesão óssea lítica. A biópsia revelou osteomielite granulomatosa. A cultura da lesão identificou Mycobacterium tuberculosis. Os autores recomendam que médicos clínicos incluam a TB como um diagnóstico diferencial da causa primária das lesões ósseas líticas, mesmo na ausência de sintomas pulmonares ou fatores de risco de infecção por TB. A inclusão de culturas micobacterianas na análise de biópsias de lesões ósseas líticas também é recomendada.

Tuberculous osteomyelitis is an uncommon form of tuberculosis (TB); the isolated involvement of TB in the wrist joint is particularly rare. The symptoms and clinical manifestation mimic other conditions; hence, careful diagnosis is required. The authors present two cases of patients presenting with soft tissue mass and a lytic bone lesion. The biopsy revealed granulomatous osteomyelitis. Lesion culture identified Mycobacterium tuberculosis. The authors urge clinicians to include TB as a differential diagnosis when investigating the primary cause of lytic bone lesions, even in the absence of pulmonary symptoms or risk factors of TB infection. The inclusion of mycobacterial cultures when analyzing biopsies of lytic bone lesions is also advised.

tuberculosis

- osteoarticular/ diagnosis

- anti-bacterial agents/ therapeutic use

\footnotetext{
Estudo conduzido no Departamento de Cirurgia Ortopédica e Traumatológica, Sanglah General Hospital-Medical Faculty of Udayana University, Denpasar, Indonésia. Originalmente Publicado por Elsevier Editora Ltda.
}

recebido

05 de Novembro de 2017

aceito

06 de Novembro de 2017
DOI https://doi.org/

10.1016/j.rboe.2017.11.015. ISSN 0102-3616.
Copyright $\odot 2019$ by Sociedade Brasileira License terms de Ortopedia e Traumatologia. Published by Thieme Revinter Publicações Ltda, Rio de Janeiro, Brazil 


\section{Introdução}

Dentre as causas das lesões ósseas líticas, estão processos benignos, malignos, ou infecciosos. 0 diagnóstico e o tratamento preciso dessas lesões exigem amplo diagnóstico diferencial e observação astuta. Muitos dos exames que distinguem essas doenças requerem material fresco e/ou estéril; portanto, é essencial ter consciência das possíveis etiologias dessas lesões e solicitar prospectivamente os exames diagnósticos corretos para evitar procedimentos diagnósticos ou tratamentos adicionais.

A tuberculose (TB) tem a capacidade de mimetizar os sintomas de muitas outras doenças, inclusive outras infecções e vários tipos de câncer. A tuberculose óssea é uma forma pouco frequente, responsável por 1 a $2 \%$ de todos os casos de TB no mundo ocidental. ${ }^{1} \mathrm{O}$ acometimento da articulação do punho é raro e, isolado, é responsável por apenas $1 \%$ de todos os casos de TB osteoarticular periférica. ${ }^{2}$ Embora rara, a TB óssea é uma causa importante de lesões ósseas líticas. $O$ diagnóstico pode ser facilmente perdido, o que leva a tratamentos inadequados e não benéficos. Apresentamos dois casos de pacientes com massa em partes moles e lesão óssea lítica. A biópsia revelou o diagnóstico de osteomielite granulomatosa. A cultura de lesão identificou Mycobacterium tuberculosis.

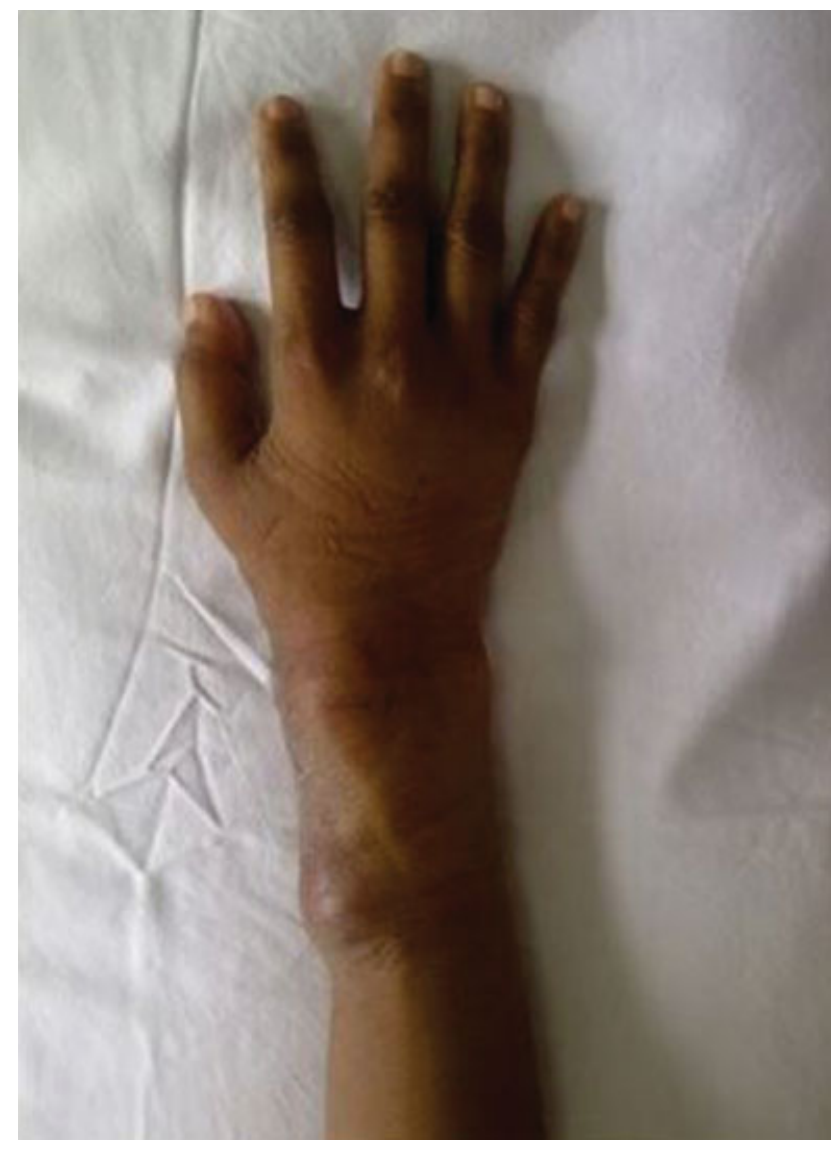

Fig. 1 Mulher de 27 anos com osteomielite tuberculosa no punho direito. A fotografia clínica do punho direito mostra uma massa no aspecto dorsomedial com dimensão de aproximadamente $3 \times 3 \mathrm{~cm}$, macia, com bordas bem-definidas, e dolorosa.

\section{Relato de Caso}

\section{Caso 1}

Uma paciente do sexo feminino, de 27 anos, foi encaminhada por um médico residente com suspeita de tumor de células gigantes (TCG) do punho direito. A paciente queixava-se de dor no punho direito há 3 meses. A paciente também relatou que, depois de 2 meses, um aumento de volume no punho direito estava ficando maior ( - Fig. 1). Não havia histórico de trauma, febre, perda de peso ou outros sintomas sistêmicos. Não havia histórico familiar de tumor ou doença crônica.

Ao exame físico, a paciente apresentava boas condições gerais e sinais vitais normais. No punho direito, encontramos uma massa dorsomedial de cerca de $3 \times 3 \mathrm{~cm}$. A massa era flexível, bem delineada, com a mesma cor da pele da paciente, e macia. A amplitude de movimento do punho direito era limitada. Os demais achados do exame foram normais.

Os exames laboratoriais revelaram aumento da velocidade de sedimentação (VHS) e da concentração de proteína C reativa (PCR) (PCR; VHS I, $25 \mathrm{~nm}$; VHS II, $100 \mathrm{~nm}$; PCR, $45 \mathrm{mg} / \mathrm{L}$ ). A radiografia simples do punho direito revelou uma lesão lítica com edema de partes moles, interpretada como suspeita de TCG pelo radiologista ( - Fig. 2). À biópsia aberta, porém, a amostra foi interpretada como osteomielite granulomatosa. Células tumorais não foram observadas ( - Fig. 3). A cultura de lesão identificou a presença de $M$. tuberculosis.

Com base nos resultados da patologia e da microbiologia, o diagnóstico de osteomielite tuberculosa do punho direito foi estabelecido. 0 tratamento foi iniciado com isoniazida

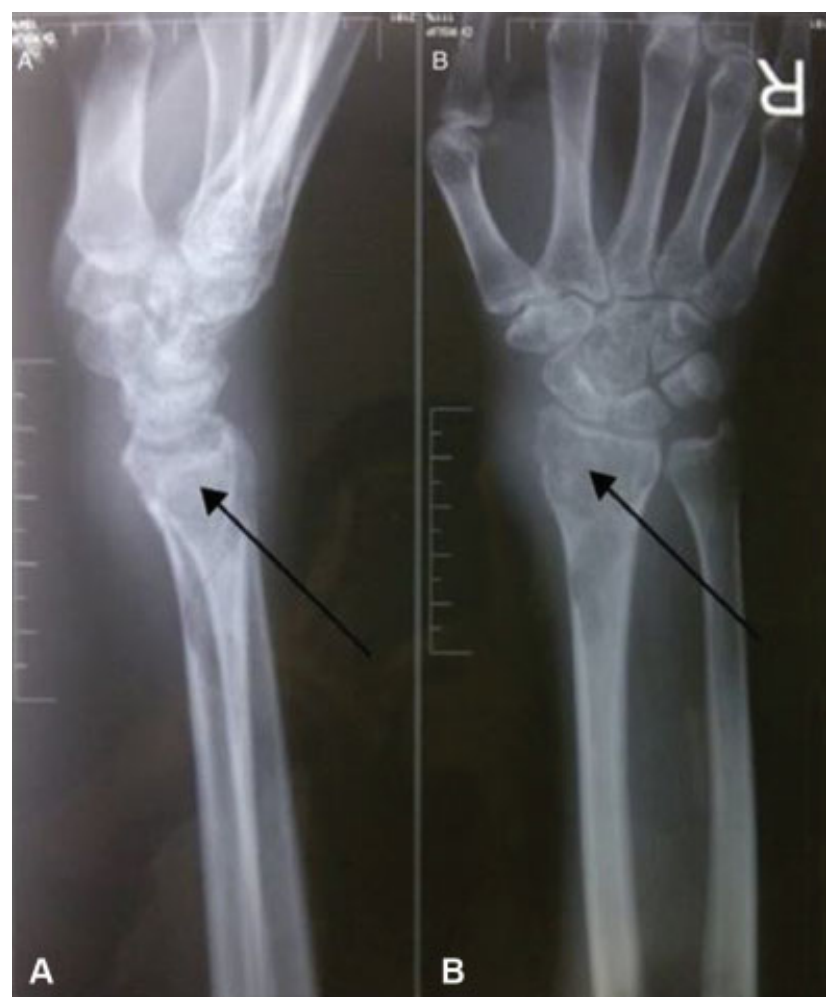

Fig. 2 Mulher de 27 anos com osteomielite tuberculosa no punho direito. Radiografias simples em perfil (A) e anteroposterior (B) do punho direito revelaram uma lesão lítica de tecido mole, com diagnóstico suspeito de tumor de células gigantes (GCT). 


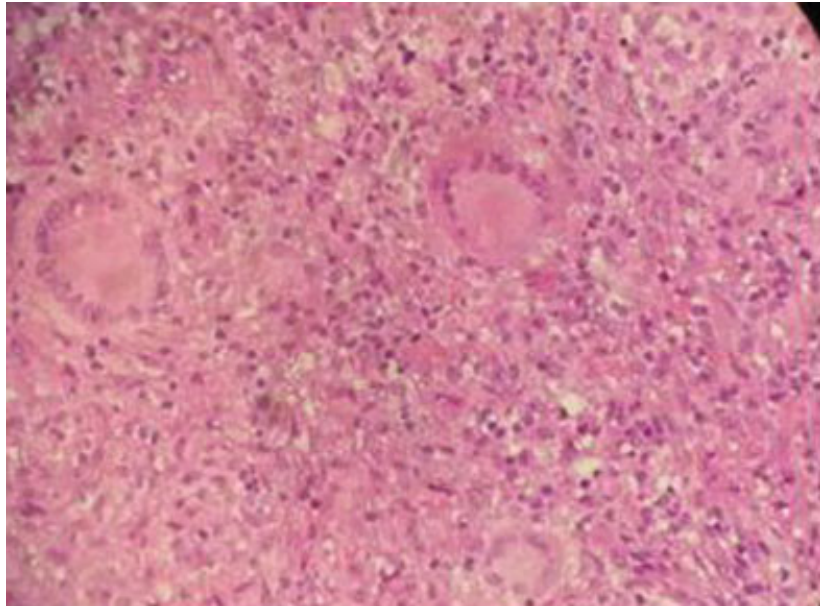

Fig. 3 Exame histopatológico de mulher de 27 anos com osteomielite tuberculosa no punho direito. Área caseosa central cercada por macrófagos e linfócitos, mas sem células tumorais.

(10 mg/kg/dia), rifampicina (10 mg/kg/dia), pirazinamida (15 mg/kg/dia), e etambutol ( $15 \mathrm{mg} / \mathrm{kg} /$ dia) com observação direta. Atualmente, a paciente demonstra melhora clínica.

\section{Caso 2}

Um paciente do sexo masculino, de 44 anos, foi encaminhado por cirurgião geral com suspeita de tumor maligno no punho direito. $O$ paciente se queixava de um aumento de volume no punho direito há 1 ano (-Fig. 4). A princípio, o aumento de volume era pequeno, mas estava ficando maior. $O$ paciente também se queixava de dor no punho direito há 6 meses. Não havia histórico de trauma, febre, perda de peso ou outros sintomas sistêmicos. Não havia histórico familiar de tumor ou doença crônica.

Ao exame físico, o paciente apresentava boas condições gerais e sinais vitais normais. No punho direito, havia uma massa de cerca de $10 \times 10 \mathrm{~cm}$. A massa era macia, com bordas mal definidas, da mesma cor da pele do paciente, e macia. A amplitude de movimento do punho direito era limitada. Os demais achados do exame foram normais.

Os exames laboratoriais revelaram aumento de VHS e PCR (VHS I, $19 \mathrm{~nm}$; VHS II, $90 \mathrm{~nm}$; PCR, $40 \mathrm{mg} / \mathrm{L}$ ). A radiografia simples do punho revelou a presença de uma lesão lítica no aspecto distal do rádio, na ulna e no carpo com aumento de volume de tecido mole (-Fig. 5). À biópsia aberta, porém, a amostra foi interpretada como osteomielite granulomatosa.

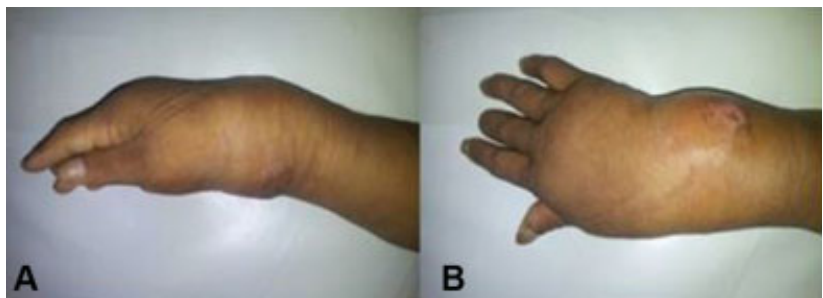

Fig. 4 Homem de 44 anos com osteomielite tuberculosa no punho direito. Radiografias simples em perfil (A) e anteroposterior (B) do punho direito revelaram um aumento de volume com tamanho aproximado de $10 \times 10 \mathrm{~cm}$, macia, com bordas mal definidas e dolorosa.

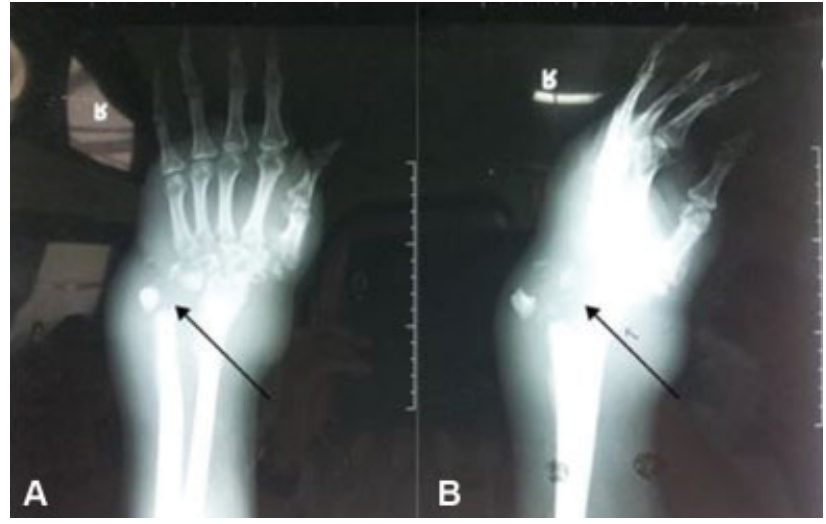

Fig. 5 Homem de 44 anos com osteomielite tuberculosa no punho direito. Radiografias simples anteroposterior (A) e em perfil (B) do punho direito revelaram uma lesão lítica no aspecto distal do rádio, na ulna e no carpo, com aumento de volume de tecidos moles.

Células tumorais não foram observadas (-Fig. 6). A cultura de lesão identificou a presença de $M$. tuberculosis.

Com base nos resultados da patologia e da microbiologia, o diagnóstico de osteomielite tuberculosa do punho direito foi estabelecido. 0 tratamento foi iniciado com isoniazida $(10 \mathrm{mg} / \mathrm{kg} / \mathrm{dia})$, rifampicina $(10 \mathrm{mg} / \mathrm{kg} / \mathrm{dia})$, pirazinamida (15 mg/kg/dia) e etambutol ( $15 \mathrm{mg} / \mathrm{kg} /$ dia) com observação direta. Também realizamos debridamento e artrodese do punho.

\section{Discussão}

A tuberculose continua a ser um importante problema de saúde global. Embora a manifestação mais comum dessa infecção seja a TB pulmonar, a TB extrapulmonar (TBEP) é observada em $20 \%$ de todos os casos de TB. A TB espinhal é a patologia mais frequente entre os casos de TB esquelética, enquanto a osteomielite tuberculosa extraespinhal é rara. ${ }^{3}$ É responsável por apenas 2 a $3 \%$ de todos os casos de TB osteoarticular. Além disso, é incomum nos casos da doença

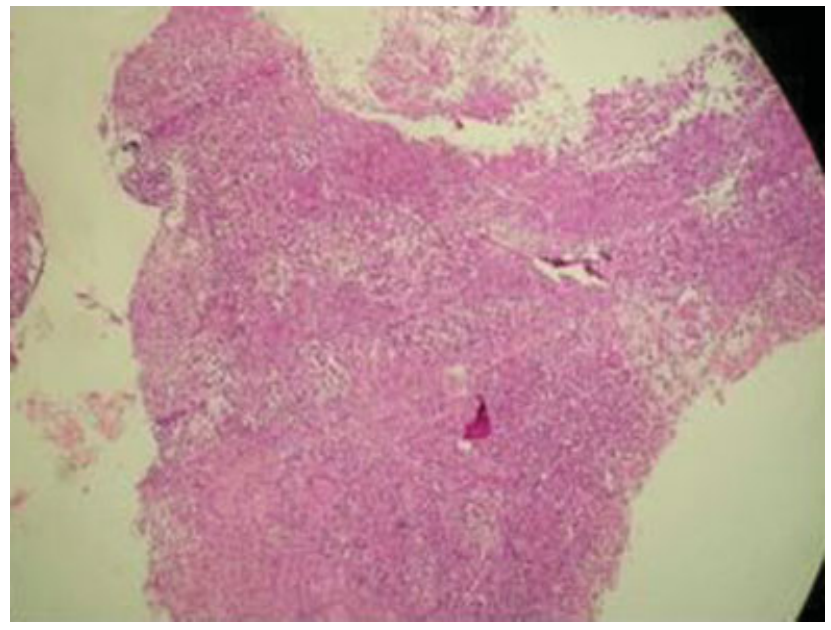

Fig. 6 Exame histopatológico de homem de 44 anos com osteomielite tuberculosa no punho direito. Área caseosa central cercada por macrófagos e linfócitos, mas sem células tumorais. 
com acometimento ósseo isolado. O acometimento ósseo é mais frequente nas articulações do quadril e do joelho. 0 envolvimento isolado do punho é raro, representando apenas $1 \%$ de todos os casos de TB osteoarticular periférica. ${ }^{2,4}$

A TB óssea é provocada por uma infecção hematogênica; assim, teoricamente, é capaz de infectar todas as partes ósseas. Durante a micobateremia da infecção primária, as bactérias ficam alojadas no osso. A resposta imune pode restringir a infecção nesses locais, mas não a erradicar. Em um dos casos aqui apresentados, o paciente apresentava uma lesão lítica no rádio distal e na ulna. O enorme suprimento vascular da placa de crescimento dos ossos longos pode predispor à infecção, ${ }^{5}$ mas a presença do processo infeccioso na metáfise distal e na epífise é incomum; dessa forma, os casos aqui relatados são únicos. ${ }^{6}$ A via alternativa de acometimento isolado da infecção óssea por TB pode ser o trauma. Soman et al. $^{7}$ relataram o caso de um paciente de 50 anos com TB osteoarticular do punho e acometimento do carpo, dos metacarpos, da ulna e do rádio. 0 paciente tinha histórico de trauma no local afetado e foi tratado por meio da colocação percutânea de pinos. No entanto, nesses casos, os pacientes não tinham histórico de trauma.

Todos os pacientes mencionados no presente estudo se queixaram de dor e aumento de volume progressivo no punho direito, sem febre ou outros sintomas sistêmicos. Segundo a literatura, inicialmente os sintomas não são específicos, como dor nas articulações, aumento de volume, efusão, rigidez e limitação de movimento. ${ }^{8}$ Em um estudo de Ali et al. ${ }^{9}$ com 66 pacientes com TB osteoarticular extraespinhal, os sintomas mais frequentes foram aumento de volume e dor (45,45\%). Sintomas constitucionais, como febre baixa, sudorese noturna, perda de peso e anorexia, geralmente não são observados. Os sinais de inflamação são brandos. ${ }^{10}$ Soman et al. ${ }^{7}$ também relataram um paciente com TB osteoarticular no punho esquerdo sem sintomas constitucionais. Os sintomas podem não ser consideráveis, mas a infecção crônica pode se tornar progressiva e causar destruição óssea radiograficamente evidente. ${ }^{11}$ Quanto ao diagnóstico laboratorial, os exames de sangue podem revelar concentrações normais ou ligeiramente elevadas de marcadores inflamatórios. ${ }^{8}$ Os números de leucócitos periféricos geralmente são normais e a VHS pode ser normal ou elevada. ${ }^{9} \mathrm{O}$ teste de tuberculina pode ser realizado; o resultado positivo pode ajudar em caso de suspeita de TB, mas o resultado negativo não deve descartar a possibilidade de infecção. ${ }^{7}$ Neste relato de caso, todos os pacientes apresentaram aumento de VHS e PCR, que indicam a existência de inflamação.

As principais características radiográficas da TB óssea são esclerose e lesões osteolíticas. No entanto, essas características não são específicas. Também são observadas em outras doenças, como tumores malignos, artrite inflamatória ou osteomielite piogênica. ${ }^{12}$ Além disso, sabe-se que osteopenia, estreitamento do espaço articular, edema de tecidos moles, cistos ósseos e reação perióstea são outras características da TB óssea. ${ }^{12-14}$ A tomografia computadorizada (TC) e a ressonância magnética (RM) são outras modalidades para obtenção de imagens do osso, mas não são específicas; auxiliam o diagnóstico diferencial e a avaliação da extensão da lesão. A RM define melhor os tecidos moles e a TC é indicada em lesões ósseas. Os pacientes do presente relato de caso exibem lesões líticas no aspecto distal do rádio, na ulna ou nos carpos, e edema de partes moles em radiografias simples, o que condiz com a literatura.

O exame histológico é importante para o diagnóstico. ${ }^{15}$

A biópsia da lesão óssea, da sinóvia ou da massa de tecido mole é necessária para esclarecer o diagnóstico. ${ }^{16} \mathrm{Em}$ um estudo de Enache et al. ${ }^{17}$ sobre ${ }^{18}$ casos de lesões osteoarticulares de TB, a biópsia foi diagnóstica em 18 casos, com observação de granulomas epitelioides e necrose caseosa. No estudo de Muangchan et al., ${ }^{19}$ o diagnóstico foi estabelecido por biópsia em $46,5 \%$ dos casos. O padrão ouro é a cultura de M. tuberculosis a partir do tecido ósseo. Na biópsia aberta, os pacientes deste relato de caso apresentaram osteomielite granulomatosa sem presença de células malignas e a cultura da lesão identificou o patógeno como $M$. tuberculosis. Com base nesses achados, os pacientes foram diagnosticados com osteomielite tuberculosa.

O tratamento principal para a osteomielite tuberculosa é a terapia medicamentosa anti-TB. Nas lesões em estágio avançado, com restrição permanente dos movimentos articulares, a fusão ou substituição cirúrgica da articulação pode ser indicada. ${ }^{9}$ Os pacientes deste relato de caso foram inicialmente tratados com quatro fármacos (isoniazida [10 mg/kg/ dia], rifampicina $[10 \mathrm{mg} / \mathrm{kg} / \mathrm{dia}]$, pirazinamida $[15 \mathrm{mg} / \mathrm{kg} /$ dia] e etambutol [15 mg/ $/ \mathrm{kg} /$ dia]), além de artrodese do punho ou curetagem e enxerto ósseo. 0 tratamento inicial anti-TB pode levar à resolução quase completa da doença e preservação da função. ${ }^{18} \mathrm{Na}$ maioria dos casos, a boa cicatrização com retorno da função pode ser obtida apenas com a terapia. A duração exata do tratamento ainda é motivo de controvérsia. Recomenda-se pelo menos 12 meses de terapia para a tuberculose óssea e articular. ${ }^{20,21}$ Ainda assim, a duração ideal do tratamento continua sendo objeto de considerável debate.

Os casos relatados no presente estudo enfatizam a importância do diagnóstico diferencial amplo da lesão óssea lítica. A TB óssea deve fazer parte dos diagnósticos diferenciais, principalmente nos países em que a doença é endêmica, mesmo na ausência de acometimento do sistema pulmonar e dos sintomas constitucionais da TB.

Conflitos de Interesse

Os autores declaram não haver conflitos de interesse.

\section{Referências}

1 Shah BA, Splain S. Multifocal osteoarticular tuberculosis. Orthopedics 2005;28(03):329-332

2 Turgut M. Spinal tuberculosis (Pott's disease): its clinical presentation, surgical management, and outcome. A survey study on 694 patients. Neurosurg Rev 2001;24(01):8-13

3 Wares F, Balasubramanian R, Mohan A, Sharma SK. Extrapulmonary tuberculosis: management and control. In: Agarwal SP, Chauhan LS, editors. Tuberculosis control in India. New Delhi: Directorate General of Health Services, Ministry of Health \& Family Welfare; 2005:95-114

4 Monir Madkour M. Tuberculosis. Berlin: Springer; 2004 
5 Gardam M, Lim S. Mycobacterial osteomyelitis and arthritis. Infect Dis Clin North Am 2005;19(04):819-830

6 Burnwal R, Neogi DS, D Ortho SS. . Tubercular osteomyelitis of distal ulna presenting as epiphyseal injury. Maedica (Buchar) 2012;7(03):247-250

7 Soman SM, Patel BN, Shah PD. Persistent posttraumatic wrist pain - tuberculosis infection should be in the differential diagnosis. A rare case report. J Orthop Case Rep 2015;5(04):17-20

8 Mussa MA, O'Connor EF, Waterston S, Taylor M, Iwuagwu F. Isolated tuberculosis of the wrist: a rare case of extrapulmonary tuberculosis. IJCRI 2013;4(10):541-545

9 Ali R, Jalil A, Qureshi A. Extra spinal osteoarticular tuberculosis: a case series of 66 patients from a tertiary care hospital in Karachi. J Pak Med Assoc 2012;62(12):1344-1348

10 Watts HG, Lifeso RM. Tuberculosis of bones and joints. J Bone Joint Surg Am 1996;78(02):288-298

11 Garrido G, Gomez-Reino JJ, Fernández-Dapica P, Palenque E, Prieto S. A review of peripheral tuberculous arthritis. Semin Arthritis Rheum 1988;18(02):142-149

12 Agarwal S, Caplivski D, Bottone EJ. Disseminated tuberculosis presenting with finger swelling in a patient with tuberculous osteomyelitis: a case report. Ann Clin Microbiol Antimicrob 2005; $4: 18$

13 Berney S, Goldstein M, Bishko F. Clinical and diagnostic features of tuberculous arthritis. Am J Med 1972;53(01):36-42
14 Wallace R, Cohen AS. Tuberculous arthritis: A report of two cases with review of biopsy and synovial fluid findings. Am J Med 1976; 61(02):277-282

15 Titov AG, Vyshnevskaya EB, Mazurenko SI, Santavirta S, Konttinen YT. Use of polymerase chain reaction to diagnose tuberculous arthritis from joint tissues and synovial fluid. Arch Pathol Lab Med 2004;128(02):205-209

16 Haider ALM. Bones and joints tuberculosis. Bahrain Med Bull 2007;29:1-9

17 Enache SD, Pleşea IE, Anuşca D, Zaharia B, Pop OT. Osteoarticular tuberculosis-a ten years case review. Rom J Morphol Embryol 2005;46(01):67-72

18 Chen SC, Chen KT. Updated diagnosis and management of osteoarticular tuberculosis. J Emerg Med Trauma Surg Care. 2014;1(01): $1-7$

19 Muangchan C, Nilganuwong S. The study of clinical manifestation of osteoarticular tuberculosis in Siriraj Hospital, Thailand. J Med Assoc Thai 2009;92(Suppl 2):S101-S109

20 Chandir S, Hussain H, Salahuddin N, et al. Extrapulmonary tuberculosis: a retrospective review of 194 cases at a tertiary care hospital in Karachi, Pakistan. J Pak Med Assoc 2010;60(02): 105-109

21 Agarwal A, Qureshi NA, Khan SA, Kumar P, Samaiya S. Tuberculosis of the foot and ankle in children. J Orthop Surg (Hong Kong) 2011; 19(02):213-217 